\section{Fluorescence Studies on Glyceraldehyde- 3-phosphate Dehydrogenase from Bovine Heart Muscle}

Ewa Seweryn*, Teresa Banaś, Izabela Berdowska, Bogdan Zieliński and Ireneusz Ceremuga

Wrocław Medical University, Department of Medical Biochemistry, Chalubinskiego 10, 50-368 Wrocław, Poland. Fax: (+48) 0717840085 , phone: $(+48) 0717841376$. E-mail: ewaseweryn@yahoo.com

* Author for correspondence and reprint requests

Z. Naturforsch. 56c, 1166-1168 (2001); received June 26/September 28, 2001

Glyceraldehyde-3-phosphate Dehydrogenase, ATP, Fluorescence

Glyceraldehyde-3-phosphate dehydrogenase is a glycolytic enzyme that catalyses conversion of glyceraldehyde-3-phosphate to 1,3-diphosphoglycerate. ATP has been found to have an inhibitory effect on this enzyme. To establish the interaction between the enzyme and ATP, a fluorescence technique was used. Fluorescence quenching in the presence of ATP suggests cooperative binding of ATP to the enzyme (the Hill obtained coefficient equals 2.78). The interaction between glyceraldehyde-3-phosphate dehydrogenase and ATP may control not only glycolysis but other activities of this enzyme, such as binding to the cytoskeleton.

\section{Introduction}

Glyceraldehyde-3-phosphate dehydrogenase (EC 1.2.2.12; GAPDH) is a glycolytic enzyme that catalyses the NAD-dependent oxidative phosphorylation of glyceraldehyde-3-phosphate to 1,3diphosphoglycerate (Skarzynski and Wonacott, 1988). It is a tetramer composed of identical subunits with a molecular mass of $37 \mathrm{kDa}$.

GAPDH has several different cellular activities unrelated to the glycolytic pathway. These include binding to single-stranded nucleic acids (Singh and Green, 1993; Schläfer et al., 1994), interaction with actic cytoskeleton (Wu et al., 1997; Rogalski-Wilk and Cohen, 1997) and calcium binding proteins (Caswell and Corbett, 1985; Filipek et al., 1991). GAPDH is susceptible to autophosphorylation (Wu et al., 1997) as well as to auto ADP ribosylation that is stimulated by nitric oxide (Zhang and Snyder, 1992).

Several glycolytic metabolites and other small molecules inhibit GAPDH competitively or non- competitively. Besides the well-known inhibitors of GAPDH such as AMP, ADP, ATP and heavy metal ions, other factors have been shown to inactivate the enzyme. These are $\mathrm{H}_{2} \mathrm{O}_{2}$ (Janero et al., 1994) and NO (Yasuda et al., 1998) that causes Snitrosylation (Okuma et al., 1998) and increases NAD binding to GAPDH (Wu et al., 1997).

\section{Materials and Methods}

Glyceraldehyde-3-phosphate dehydrogenase from bovine heart muscle was isolated according to Kochman et al. (1975). The enzyme was purified by CM-cellulose chromatography (Siemieniewski et al., 1984). The enzyme activity was measured in $50 \mathrm{~mm}$ triethanolamine/ $\mathrm{HCl}$ buffer $\mathrm{pH} 7.6 ; 0.9 \mathrm{~mm}$ EDTA; $1.1 \mathrm{~mm}$ ATP; $0.2 \mathrm{~mm}$ NADH; $2 \mathrm{~mm}$ $\mathrm{MgSO}_{4} ; \quad 6.1 \mathrm{~mm}$ glycerate-3-phosphate and 1.3 units/ml 3-phosphoglycerate kinase (one unit will convert $1 \mu \mathrm{mol}$ of 3-phosphoglycerate to 1,3diphosphoglycerate per min at $\mathrm{pH} 7.5,37^{\circ} \mathrm{C}$ ). The reaction was started by the addition of an appropriate amount of GAPDH solution reaching the final volume of $3.0 \mathrm{ml}$. The absorbance change at $340 \mathrm{~nm}$ was determined at $37^{\circ} \mathrm{C}$. Prior to the assay, the enzyme was diluted in $5 \mathrm{~mm}$ Tris (trishydroxymethylaminomethane $/ \mathrm{HCl}$ ) buffer, $\mathrm{pH} 7.6$, so that the total change of absorbance during 1 min would not be greater than 0.2 . The protein concentration was estimated spectrophotometrically, assuming $E_{c m}^{0.1 \%}=1$ at $280 \mathrm{~nm}$.

To investigate the effect of ATP on GAPDH activity a different test was used. The assay mixture contained the following in a final volume of $1 \mathrm{ml}$ : $1.0 \mu \mathrm{g}$ of the enzyme, $50 \mathrm{~mm}$ triethanolamine hydrochloride $\mathrm{pH} 8.6,10 \mathrm{~mm}$ sodium arsenate, $5 \mathrm{~mm}$ EDTA, $0.3 \mathrm{~mm}$ glyceraldehyde-3-phosphate, $0.3 \mathrm{~mm}$ NAD. The reaction was initiated by the addition of an appropriate amount of GAPDH solution.

The absorbance change at $340 \mathrm{~nm}$ was measured at $37^{\circ} \mathrm{C}$. One unit of the enzyme activity is defined as the amount of the enzyme required to catalyse the reduction of $1 \mu \mathrm{mol}$ of NAD per min at $37^{\circ} \mathrm{C}$.

Fluorescence measurements were made with a Perkin Elmer MPF 3L spectrofluorometer equipped with a constant temperature bath. 1-cm path length cuvette was used with the excitation set at $290 \mathrm{~nm}$ (slit $5 \mathrm{~nm}$ ). 


\section{Results and Discussion}

During incubation of GAPDH with $2 \mathrm{~mm}$ ATP in $37^{\circ} \mathrm{C}$, changes in enzymatic activity were observed. After 3 min enzymatic activity decreased by around $70 \%$.

Fluorescence intensity of the samples containing GAPDH (of a fixed volume $2.0 \mathrm{ml}$ ) with increasing amounts of ATP was recorded. In each subsequent sample the concentration of ATP increased by $100 \mu \mathrm{M}$. Addition of ATP to GAPDH solutions caused quenching of tryptophan fluorescence of the enzyme at $\lambda_{\mathrm{ex}}=290 \mathrm{~nm}$ and $\lambda_{\mathrm{em}}=340 \mathrm{~nm}$ (Fig. 1).

Data analysis by Stern-Volmer plot showed strong positive deviation from linearity, according to Fig. 2. The above figure shows a good accordance with Hill's equation (Wolosiuk and $\mathrm{Bu}$ chanan, 1976) for the cooperative ligand binding. Hill's equation:

$$
\Delta F=\frac{\Delta F_{\max }}{(1+K /[L] n}
$$

where $L$ is the ligand, $K$ the apparent overall enzyme-ligand association constant and $n-$ the apparent Hill coefficient. Constants for the most fitted curve were obtained as follows: $K=0.8 \pm$ $0.03 \mathrm{~mm}$ (err. $4.7 \%$ ), $n=2.78 \pm 0.25$ (err. 9.0\%), $\Delta$ fluorescence $_{\max }=109.5 \pm 5.2$ (err. $\left.4.8 \%\right)$.

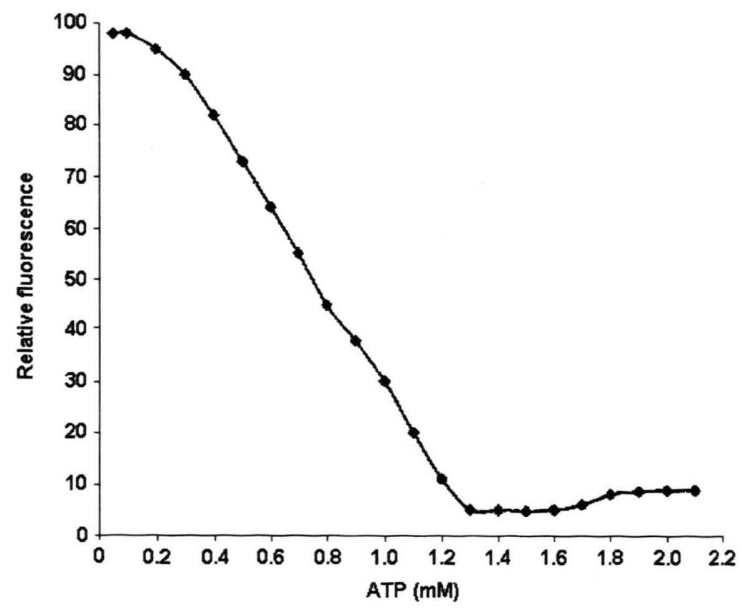

Fig. 1. The quenching of the fluorescence of the glyceraldehyde-3-phosphate dehydrogenase in ATP presence. Experimental conditions were at $37^{\circ} \mathrm{C}$ in $50 \mathrm{~mm}$ Tris buffer ( $\mathrm{pH}$ 7.6) containing $1 \mathrm{~mm}$ EDTA. Concentration of GAPDH was $50 \mu \mathrm{g} / \mathrm{ml}$.

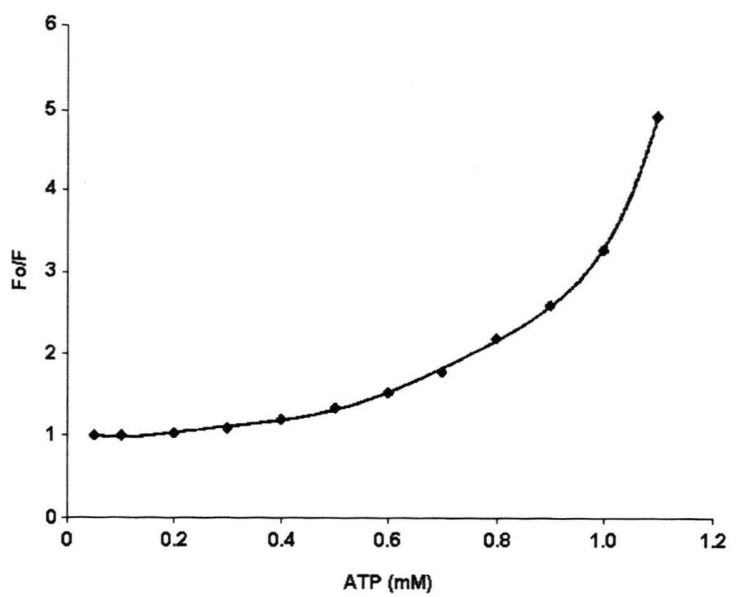

Fig. 2. Stern-Volmer plot for the quenching of the fluorescence of glyceraldehyde-3-phosphate dehydrogenase ATP complex. $F_{o}-$ fluorescence of the native enzyme, $F$ - fluorescence of the enzyme in the presence of ATP.

For most glycolytic enzymes the change of $\mathrm{pH}$ from basic into acidic during intensive work of muscles does not cause a noticeable alteration of their activity. Glycolysis continues until ATP concentration reaches the level at which phosphofructokinase and pyruvate kinase activities are inhibited. High quantities of ATP and $\mathrm{pH}$ decrease result in strong and immediate GAPDH activity inhibition, which prevents acidification of the cell. Therefore the way of interaction between ATP and GAPDH is an interesting issue. To elucidate this problem fluorescence measurements of the enzyme in the presence of increasing ATP concentration were performed. The observed quenching of tryptophan fluorescence of the enzyme results from interaction between the nucleotide and the protein. It could not be an artifact because the absorption of ATP at $\lambda_{\mathrm{ex}}=290 \mathrm{~nm}$ and $\lambda_{\mathrm{em}}=340 \mathrm{~nm}$ was insignificant, lower than 0.1 .

Strong positive deviation from linearity in a Stern-Volmer plot (Fig. 2) suggests the combination of two mechanisms of fluorescence quenching by ATP: a static and a dynamic one (Lahowicz, 1988). It could be caused by collisions of ATP molecules with the enzyme or by formation of nonfluorescent complexes of ATP with the fluorophore tryptophan. The Hill coefficient estimated as $2.78 \pm 0.25$ and the strong positive deviation from linearity (Fig. 2) suggest cooperative binding of ATP to glyceraldehyde-3-phosphate dehydro- 
genase. However, this interaction seems to be weak since fluorescence quenching by ATP was reversed after dialysis. Similar results were obtained by Krusteva et al. (1984), who demonstrated cooperative interaction between ATP and GAPDH from Chlorella (with a Hill coefficient of 2.2)

Except for ATP influence on GAPDH activity, the nucleotide affects also other properties of the enzyme (Zhang and Wang, 1999; Tatton et al., 2000). Heard et al. (1998) found that ATP caused the release of GAPDH from erythrocyte membranes by interaction with cooperative sites of the

Caswell A. H. and Corbett A. M. (1985), Interaction of glyceraldehyde-3-phosphate dehydrogenase with isolated microsomal subfractions of skeletal muscle. J. Biol. Chem. 260, 6892-6898.

Filipek A., Gerke V., Weber K. and Kuznicki J. (1991), Characterization of the cell cycle regulated protein calcyclin from Ehrlich ascites tumor cells. Eur. J. Biochem. 195, 795-800.

Heard K. S., Diguette M., Heard A. C. and Carruthers A. (1998), Membrane bound glyceraldehyde-3-phosphate dehydrogenase and multiphasic erythrocyte sugar transport. Exp. Physiol. 83, 195-202.

Janero D. R., Hreniuk D. and Sharif H. M. (1994), Hydroperoxide induced oxidative stress impairs heart muscle cell carbohydrate metabolism. Am. J. Physiol. 266. C179-188.

Kochman M., Golebiowska J., Baranowski T., Dedman J. R., Fodge D. W. and Harris B. G. (1975), Studies on enzyme from parasitic helminths V. Purification and characterization of glyceraldehyde-3-phosphate dehydrogenase from Ascaris suum muscle. Comp. Biochem. Physiol. 52B, 301-306.

Krusteva N. G., Tomova N. G. and Georgieva M. A. (1984), Allosteric regulation of NAD(NADP) dependent glyceraldehyde-3-phosphate dehydrogenase from Chlorella by $\alpha$ amino acids, dithiothreitol and ATP. FEBS Lett. 171, 137-140.

Lahowicz J. R. (1988), Principles of Fluorescence Spectroscopy. Plenum Press; New York, London.

Okuma Y., Uehara T. and Nomura Y. (1998), The precise characterization and the crucial mechanism of NO induced cytotoxicity. Nippon Yakurigaku Zasshi. 112, 187-194.

Ouporov I. I. V., Knull H. R., Lowe S. L. and Thomasson K. A. (2000), Interactions of glyceraldehyde-3-phosphate dehydrogenase with $\mathrm{G}$ and $\mathrm{F}$ actin predicted by Brownian dynamics. J. Mol. Recognit. 14, 29-41.

Rogalski-Wilk A. A. and Cohen R. S. (1997), Glyceraldehyde-3-phosphate dehydrogenase activity and $F$ actin associations in synaptosomes and postsynaptic densities of porcine cerebral cortex. Cell. Mol. Neurobiol. 17, $51-70$. enzyme. Moreover, ATP turned out to inhibit GAPDH interaction with a glucose transport protein (GLUT1). On the other hand, through autophosphorylation of GAPDH ATP increased the binding of the enzyme to actin in a high-density area of the postsynaptic structure containing cytoskeletal and regulatory proteins involved in signal transduction (Wu et al., 1997). In light of these findings it could be suggested that ATP-GAPDH interaction affects not only glycolysis but also controls other activities of the enzyme, like binding to cytoskeleton (Ouporov et al., 2000).

Schläfer M., Volknandt W. and Zimmermann H. (1994), Putative synaptic vesicle nucleotide transporter identified as glyceraldehyde-3-phosphate dehydrogernase. J. Neurochem. 63, 1924-1931.

Siemieniewski H., Golebiewski J. and Wolny M. (1984), Purification of glyceraldehyde-3-phosphate dehydrogenase. Polish Patent P.241281.

Singh R. and Green M. R. (1993), Sequence-specific binding of transfer RNA by glyceraldehyde-3-phosphate dehydrogenase. Science 259, 365-368.

Skarzynski T. and Wonacott A. J. (1988), Coenzyme induced conformational changes in glyceraldehyde-3phosphate dehydrogenase from Bacillus stearothermophilus. J. Mol. Biol. 203, 1097-1118.

Tatton W. G., Chalmers-Redman R. M., Elstner M., Leesch W., Jagodzinski F. B., Stupak D. P., Sugrue M. M. and Tatton N. A. (2000), Glyceraldehyde3-phosphate dehydrogenase in neurodegeneration and apoptosis signaling. J. Neural. Trans. Suppl. 60, $77-100$.

Wolosiuk R. A. and Buchanan B. B. (1976), Studies on the regulation of chloroplast NADP linked glyceraldehyde-3-phosphate dehydrogenase. J. Biol. Chem. 251, 6456-6461.

Wu K., Aoki C., Elste A., Rogalski-Wilk A. A. and Siekevitz P. (1997), The synthesis of ATP by glycolytic enzymes in the postsynaptic density and the effect of endogenously generated nitric oxide. Proc. Natl. Acad. Sci. USA. 94, 13273-13278.

Yasuda M., Fujimori H. and Panhou H. (1998), NO depletes cellular ATP contents via inactivation of glyceraldehyde-3-phosphate dehydrogenase in PC12 cells. J. Toxicol. Sci. 23, 389-394.

Zhang J. and Snyder S. H. (1992), Nitric oxide stimulates auto ADP ribosylation of glyceraldehyde 3 phosphate dehydrogenase. Proc. Natl. Acad. Sci. USA 89, 9382-9385.

Zhang N. X. and Wang C. (1999), A stable cold folding intermediate of rabbit muscle D glyceraldehyde-3phosphate dehydrogenase. Eur. J. Biochem. 264, $1002-1008$. 